\title{
Application of E/Z-Isomerization Technology for Enhancing Processing Efficiency, Health-Promoting Effects, and Usability of Carotenoids: A Review and Future Perspectives
}

\author{
Masaki Honda* \\ Faculty of Science \& Technology, Meijo University, 1-501 Shiogamaguchi, Tempaku-ku, Nagoya, Aichi 468-8502, JAPAN
}

\begin{abstract}
Carotenoids are naturally occurring pigments whose presence in the diet is beneficial to human health. Moreover, they have a wide range of applications in the food, cosmetic, and animal feed industries. As carotenoids contain multiple conjugated double bonds in the molecule, a large number of geometric $(E / Z$, trans/cis) isomers are theoretically possible. In general, (all- $E$ )-carotenoids are the most predominant geometric isomer in nature, and they have high crystallinity and low solubility in various mediums, resulting in their low processing efficiency and bioavailability. Technological developments for improving the processing efficiency and bioavailability of carotenoids utilizing the $Z$-isomerization have recently been gaining traction. Namely, $Z$-isomerization of carotenoids induces a significant change in their physicochemical properties (e.g., solubility and crystallinity), leading to improved processing efficiency and bioavailability as well as several biological activities. For the practical use of isomerization technology for carotenoids, the development of efficient isomerization methods and an acute understanding of the changes in biological activity are required. This review highlights the recent advancements in various conventional and unconventional methods for carotenoid isomerization, such as thermal treatment, light irradiation, microwave irradiation, and catalytic treatment, as well as environment-friendly isomerization methods. Current progress in the improvement of processing efficiency and biological activity utilizing isomerization technology and an application development of carotenoid $Z$-isomers for the feed industry are also described. In addition, future research challenges in the context of carotenoid isomerization have been elaborated upon.
\end{abstract}

Key words: carotenoid, E/Z-isomerization, solubility, crystallinity, processing, bioavailability, biological activity, application

\section{Introduction}

Carotenoids are naturally occurring lipid-soluble pigments responsible for imparting color to plants, animals, algae, and photosynthetic bacteria, and approximately 850 types of carotenoids have been discovered and characterized in nature until 2018, ${ }^{12}$. In recent years, they have been studied with much interest, as their dietary intake and high serum concentrations are associated with a lower risk of various diseases, such as cancers, cardiovascular diseases, and eye diseases ${ }^{3-5}$. Furthermore, several carotenoids have effects to enhance flesh and egg yolk color of seafoods and laying hens ${ }^{6,7)}$, and to improve human skin quality and protect humans against ultraviolet(UV) radiation-induced skin damage ${ }^{8,9)}$. Therefore, carotenoids offer a wide range of applications, not only in foods but also in animal feeds and cosmetics. These varied applications have enhanced the demand for carotenoid-rich products; their global market was valued at USD 1.5 billion in 2019 and is forecasted to reach USD 2.0 billion in 2027, at a compound annual growth rate (CAGR) of $4.2 \%$ during this period ${ }^{10)}$.

The bioavailability of carotenoids is generally very low because of their unique physicochemical properties (e.g., high hydrophobicity and crystallinity $)^{11,12)}$, which has posed a serious problem in their industrial use. To improve

\footnotetext{
*Correspondence to: Masaki Honda, Faculty of Science \& Technology, Meijo University, 1-501 Shiogamaguchi, Tempaku-ku, Nagoya, Aichi 468-8502, JAPAN

E-mail: honda@meijo-u.ac.jp ORCID ID: https://orcid.org/0000-0001-9470-7442

Accepted November 9, 2021 (received for review October 30, 2021)

Journal of Oleo Science ISSN 1345-8957 print / ISSN 1347-3352 online

http://www.jstage.jst.go.jp/browse/jos/ http://mc.manusriptcentral.com/jjocs

This is the review by the winner of $55^{\text {th }}$ Award for Prominent Studies, The Japan Oil Chemists' Society (JOCS).

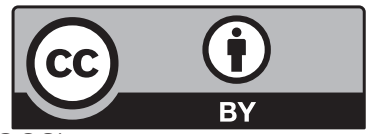




\section{Honda}

carotenoid bioavailability, water dispersion and fine grinding processes have traditionally been developed ${ }^{12,13)}$. Recently, "geometric (E/Z, trans/cis) isomerization technology" has received much attention. As carotenoids contain multiple conjugated double bonds in the molecule, a large number of geometric isomers are theoretically possible (Fig. 1 $)^{14,15)}$. However, most of carotenoids occur as the all- $E$-isomer in plants and microorganisms, e.g., $>90 \%$ of the total lycopene in tomatoes and the total astaxanthin in Paracoccus carotinifaciens exist as the all- $E$-isomer ${ }^{7,14)}$. In contrast, carotenoids in the living body have a large amount of the $Z$-isomers, e.g., in human blood, $>50 \%$ and $>30 \%$ of the total lycopene and astaxanthin exist as the $Z$-isomers, respectively ${ }^{3,14)}$. Several human trials demonstrated that $Z$-isomers of carotenoids are more bioavailable than the naturally predominant all- $E$-isomers ${ }^{16-18)}$, e.g., Cooperstone $e t a l{ }^{16)}$ evaluated the effects of ingesting red tomato juice (total $Z$-isomer ratio of lycopene $=10 \%$ ) and tangerine tomato juice (total $Z$-isomer ratio of lycopene $=$ $94 \%$ ) on plasma lycopene concentrations in humans, and found that the tangerine tomato juice-derived lycopene exhibited an approximately 8.5-fold higher bioavailability than the red tomato juice-derived one. In addition, in vitro and in vivo studies with other carotenoids, such as astaxanthin and lutein, demonstrated higher bioavailability of their $Z$-isomers ${ }^{19-21)}$. Moreover, recent studies have suggested that carotenoid $Z$-isomers possess greater biological activities, such as antioxidant, anti-inflammatory, and anticancer activities, than the all- $E$-isomers (note that carotenoid $Z$-isomerization could have negative effects in some cases, e.g., for $\beta$-carotene, the $Z$-isomers would have lower bioavailability and provitamin A activity than the all- $E$-isomer $)^{14,21-25)}$. Hence, with a few exceptions, it is preferable to use carotenoid $Z$-isomers rather than the all- $E$-isomer in industry, and thus the development of efficient and practicable isomerization methods is very important.

This review highlights efficient methods for carotenoid $Z$-isomerization, focusing specifically on the technology de- veloped by our group. Carotenoid $Z$-isomers have been traditionally prepared from the all- $E$-isomers via thermal and catalytic isomerization, using methods that involve toxic organic solvents and catalysts (e.g., iodine and heavy metals), coupled with extensive treatment periods ${ }^{14,26)}$. We have developed efficient and environmentally friendly methods for carotenoid isomerization, such as methods using vegetable oils and supercritical $\mathrm{CO}_{2}$ as an alternative to organic solvents, as well as incorporating plant-derived catalysts $^{27-29)}$. Furthermore, recent progress in developing the value and applications of isomerization technology and $Z$-isomer-rich carotenoid materials also be discussed. For example, as the $Z$-isomerization of carotenoids results in a significant change in their physicochemical properties (e.g., solubility and crystallinity) ${ }^{30,31)}$, their processing efficiency (e.g., extraction and micronization) can be improved by utilizing this effect ${ }^{26,32,33)}$. In addition, the feeding of a carotenoid $Z$-isomer-rich diet to laying hens improves egg yolk pigmentation compared to that of an all- $E$-isomer-rich one ${ }^{34,35)}$, thereby indicating the potential of $Z$-isomer-rich carotenoid materials in the feed industry. From the above, it evident that a comprehensive understanding of the isomerization technology, including $Z$-isomerization methods and differences in physicochemical characteristics and biological activities between the $E / Z$-isomers, should facilitate a more effective utilization of these valuable compounds across various industrial fields.

\section{Methods for Carotenoid Isomerization}

To date, several methods for $E / Z$-isomerization of carotenoids, such as thermal treatment ${ }^{36,37)}$, light irradiation ${ }^{38,39)}$, microwave irradiation $^{40,41)}$, and catalytic treatment ${ }^{42,43)}$, are well documented in the literature. As the isomerization efficiency of carotenoids varies greatly among treatments ${ }^{14,26)}$, it is important to accurately understand the characteristics of each isomerization method. Carotenoid isomerization is

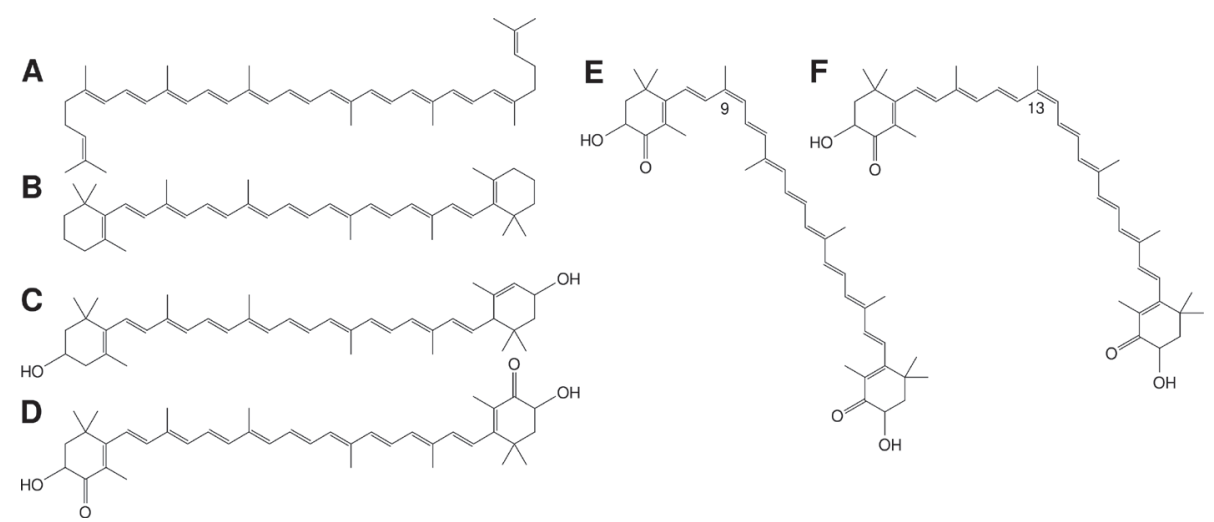

Fig. 1 Chemical structures of (A) (all-E)-lycopene, (B) (all-E)- $\beta$-carotene, (C) (all- $E$ )-lutein, (D) (all-E)-astaxanthin, (E) (9Z)astaxanthin, and (F) (13Z)-astaxanthin. 
generally conducted in organic solvents because the reaction proceeds efficiently in their dissolved states ${ }^{36-39,42-44)}$. For example, heating tomato powder at $140^{\circ} \mathrm{C}$ for $5 \mathrm{~min}$ induced negligible $Z$-isomerization of lycopene (total $Z$-isomer ratio of $\langle 10 \%)^{45)}$, but heating (all- $E$ )-lycopene solution dissolved in ethyl acetate at $140^{\circ} \mathrm{C}$ for $30 \mathrm{~s}$ induced efficient $Z$-isomerization (total $Z$-isomer ratio of $>50 \%)^{44)}$. Recently, consumers have increasingly demanded the discontinuation of the use of chemicals, including organic solvents, in the food production process. Accordingly, the development of toxic chemical-free and environmentally friendly methods for carotenoid isomerization has attracted much attention. This section addresses various isomerization methods and their characteristics, with special focus on environmentally friendly isomerization methods.

\subsection{Thermal treatment}

Carotenoid $Z$-isomerization via thermal treatment is the most common method employed due to its convenience and effective cost performance ${ }^{14,26)}$. In general, the thermal isomerization of carotenoids occurs in organic solvents at temperatures not higher than their boiling point, and the type of solvent has a great influence on the isomerization efficiency $^{36,37,42,46)}$. Specifically, when halogen solvents, such as chloroform $\left(\mathrm{CHCl}_{3}\right)$ and dibromomethane $\left(\mathrm{CH}_{2} \mathrm{Br}_{2}\right)$, are used as the medium, the $Z$-isomerization efficiency by heating is high compared to using other common solvents, such as acetone, hexane, and benzene ${ }^{36,42,46)}$. For example, when (all- $E$ )-lycopene was dissolved in acetone and $\mathrm{CH}_{2} \mathrm{Br}_{2}$ and heated at $50^{\circ} \mathrm{C}$ for $12 \mathrm{~h}$, the total $Z$-isomer ratio increased to approximately 40 and $80 \%$, respectively ${ }^{36)}$. However, the use of halogen solvents is typically banned in food and cosmetic manufacturing processes because of their high toxicity. Thus, Generally Recognized as Safe
(GRAS) solvents with low toxicity, such as ethanol and ethyl acetate, should be used in the isomerization process when assuming practical applications. However, it is difficult to achieve efficient isomerization using these GRAS solvents from the perspective of the total $Z$-isomer ratio and processing time ${ }^{36,42,46)}$. Moreover, the conventional isomerization method involves inefficient batch systems. Recently, we successfully developed a continuous and efficient carotenoid isomerization procedure using a flow reactor (Fig. 2A ${ }^{44,47,48)}$. The continuous-flow method can easily control the reaction, is capable of high-temperature as well as high-pressure processing, and is environmentally friendly owing to the omission of the hold step and its low energy consumption ${ }^{49)}$. For example, when (all- $E$ ) -astaxanthin solution in ethanol was treated at $200^{\circ} \mathrm{C}$ and $10 \mathrm{MPa}$ with a continuous-flow reactor, the total $Z$-isomer ratio achieved $>60 \%$ in only $30 \mathrm{~s}$ (Figs. 2B-D) ${ }^{47)}$. Conversely, such high-temperature processing induces significant carotenoid degradation, thus necessitating the addition of antioxidants, such as ascorbic acid and $\alpha$-tocopherol, in the system to inhibit thermal degradation ${ }^{44,47,48)}$.

We have also reported organic solvent-free methods for carotenoid isomerization; for example, vegetable oils and sub- and supercritical fluids ${ }^{27-29,50,51)}$. When tomato puree was heated at $120^{\circ} \mathrm{C}$ for $1 \mathrm{~h}, Z$-isomerization of (all- $E$ )-lycopene did not proceed, whereas when $>1 \%$ of olive oil was added, the thermal $Z$-isomerization occurred efficiently, achieving a total $Z$-isomer ratio $>50 \%$ by treatment at $120^{\circ} \mathrm{C}$ for $1 \mathrm{~h}$ with $3 \%$ of olive oil ${ }^{50)}$. Moreover, we observed that the thermal $Z$-isomerization efficiency varied significantly depending on the type of vegetable oils used ${ }^{27,28)}$. Specifically, when a tomato extract was diluted with olive, sunflower, corn, roasted sesame, and mustard oils (lycopene concentration, $3.75 \%$ ), the total $Z$-isomer ratio after
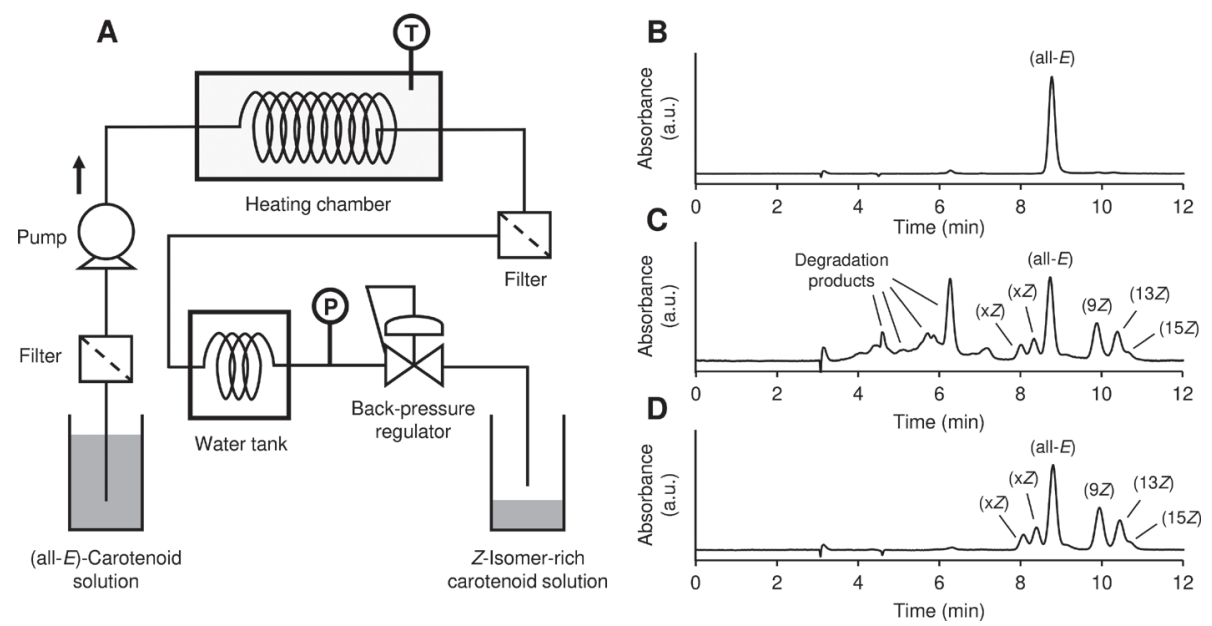

Fig. 2 (A) Schematic diagram of the continuous-flow reactor for carotenoid isomerization ${ }^{44,47,48)}$ and normal-phase HPLC chromatograms of astaxanthin isomers (B) before and after treatment at $200^{\circ} \mathrm{C}$ and $10 \mathrm{MPa}$ for $30 \mathrm{~s}$ in the $(\mathrm{C})$ absence and (D) presence of $10 \mathrm{mM}$ ascorbic $\operatorname{acid}^{47)}$ : (all-E), (9Z), (13Z), and (15Z) in the chromatograms denote (all- $E$ )-, (9Z) -, (13Z) -, and (15Z) -astaxanthin, and (xZ) denotes unknown astaxanthin $Z$-isomer. 


\section{Honda}

heating at $140^{\circ} \mathrm{C}$ for $1 \mathrm{~h}$ increased to $42.9,43.1,44.2,57.3$, and $69.5 \%$, respectively, that is, roasted sesame and mustard oils significantly enhanced thermal $Z$-isomerization of lycopene compared to other vegetable oils ${ }^{27)}$. This thermal $Z$-isomerization-promoting ability of roasted sesame and mustard oils would be attributed to the isothiocyanates and polysulfides contained in them (see section “2.4” $)^{40,42,52)}$.

Supercritical $\mathrm{CO}_{2}$ and subcritical water can also be used as a medium to promote thermal $Z$-isomerization of carotenoids $^{29,51)}$. For instance, Watanabe et $a l .{ }^{29)}$ demonstrated that when lycopene was extracted from dried tomato pulp using supercritical $\mathrm{CO}_{2}$ at 50 or $80^{\circ} \mathrm{C}$, the total $Z$-isomer ratio of lycopene in the resulting extract was significantly higher at $80^{\circ} \mathrm{C}$. Supercritical $\mathrm{CO}_{2}$ is non-toxic and can prevent contact with atmospheric oxygen, which minimizes degradation of the labile components ${ }^{53)}$. Therefore, this green solvent is suitable as a medium for carotenoid processing, including the $Z$-isomerization. We recently demonstrated that subcritical water can be used as a medium to promote the $Z$-isomerization of carotenoids (astaxanthin, adonirubin, and adonixanthin), but as their degradation is markedly accelerated during processing, countermeasures are necessary $^{51)}$. Very few reports exist on carotenoid $Z$ isomerization using green solvents including supercritical $\mathrm{CO}_{2}$, and further research in this field is expected in the future. Incidentally, it has been reported that heating (all- $E$ )-lycopene at temperatures above its melting point promoted the $Z$-isomerization without a medium, indicating that carotenoid $Z$-isomerization might be enhanced in their molten state ${ }^{45)}$.

\subsection{Light irradiation}

Several studies have demonstrated that light irradiation induces carotenoid isomerization, primarily $Z$ - to $E$-isomerization $^{38,54,55)}$. For example, when (all- $E$ )-astaxanthin solution in ethanol was exposed to fluorescent light at $30^{\circ} \mathrm{C}$ for 21 days, the total $Z$-isomer ratio increased to only approximately $10 \%$, whereas when $Z$-isomer-rich astaxanthin (total $Z$-isomer ratio $=89.5 \%$ ) solution in ethanol was exposed to light under the same conditions, the total $Z$-isomer ratio markedly decreased to approximately $10 \%{ }^{54)}$. This isomerization trend was also observed for other carotenoids, such as lycopene, $\beta$-carotene, adonirubin, and adonixanthin ${ }^{38,54,55)}$. Thus, under light exposure, the equilibrium of the $E / Z$ isomerization of carotenoids is considered to be biased toward the all- $E$-isomer side. This fact suggests the possibility of arbitrary control of the isomer ratio of carotenoids by combining thermal and photoisomerization. On the other hand, when light irradiation was conducted in the presence of photosensitizers, such as chlorophyll $a$, rose bengal, and erythrosine, (all- $E$ )-carotenoids efficiently isomerized to the $Z$-isomers ${ }^{39,56)}$. For instance, our group demonstrated that when (all-E)-lycopene solutions in acetone were exposed to light with a wavelength of 480-600 nm for $1 \mathrm{~h}$-in the absence and presence of photosensitizers, rose bengal and erythrosine-the total $Z$-isomer ratios increased to $7.7,46.4$, and $47.7 \%$, respective$\mathrm{ly}^{39)}$. These results indicate that the singlet excited state of carotenoids induced by direct light irradiation might enhance $Z$ - to $E$-isomerization, whereas the triplet excited state induced by light irradiation with photosensitizers might enhance the opposite reaction ${ }^{14)}$. As a side note, the iodine-catalyzed photoisomerization of carotenoids is traditionally carried out to promote their $Z$-isomerization, but the isomerization mechanism is thought to be a radical process principally $^{57,58)}$.

\subsection{Microwave irradiation}

Microwave irradiation has been studied extensively as an efficient method for carotenoid $Z$-isomerization ${ }^{40,41,59)}$ because it is capable of rapidly and uniformly heating a heated body. The $Z$-isomerization mechanism via microwave irradiation is considered to be similar to conventional heat treatment; however, several studies have indicated that the efficiency of $Z$-isomerization is higher with microwave irradiation than with heat treatment. For example, Kessy et $a l .{ }^{59)}$ reported that when lycopene solution in ethyl acetate was refluxed with or without microwave irradiation for $5 \mathrm{~h}$, the total $Z$-isomer ratio after reflux with microwave irradiation was higher than that without the irradiation. We also demonstrated the high efficiency of lycopene $Z$-isomerization with microwave irradiation, i.e., when tomato oleoresin was treated by conventional oil-bath heating at $140^{\circ} \mathrm{C}$ for $5 \mathrm{~min}$ and microwave heating at $500 \mathrm{~W}$ for $4 \mathrm{~min}$ (the temperature of the oleoresin reached $136.7^{\circ} \mathrm{C}$ ), the total $Z$-isomer ratios attained were 50.8 and $65.9 \%$, respectively ${ }^{40)}$. Further research is necessary to elucidate the reason for the high isomerization efficiency of microwave irradiation. Microwave irradiation is an effective method for carotenoid isomerization; however, as precise control of the reaction is considered difficult, further measures are required for practical use.

\subsection{Catalytic treatment}

There have been several reports on carotenoid $Z$-isomerization using catalysts, resulting in high $Z$-isomerization efficiency ${ }^{14,26)}$. However, a majority of these previous studies used highly toxic heavy metal catalysts, such as iron(III) chloride, copper (II) chloride, and titanium tetrachloride ${ }^{43,60-62)}$. In recent studies conducted by us, specific food ingredients were observed to possess $Z$-isomerization-promoting effects and the causative agents, such as isothiocyanates and polysulfides, were successfully identified ${ }^{52,63,64)}$. Specifically, we investigated the effect of 131 food ingredients (fresh vegetables, fresh mushrooms, dried spices, and dried seaweeds) on the total $Z$-isomer ratio of lycopene in tomato puree containing $5 \%$ olive oil after heating at $80^{\circ} \mathrm{C}$ 
for $1 \mathrm{~h}$. The results of this test revealed that specific vegetables, such as Allium sp.(e.g., garlic, onion, and leek), Brassica sp. (e.g., cabbage, broccoli, and mustard), and Raphanus sp. (e.g., radishes and wasabi), a mushroom (Lentinus edodes; shiitake mushroom), and specific seaweeds, such as Saccharina sp. (e.g., ma-kombu and gagome-kombu), enhanced thermal $Z$-isomerization of tomato lycopene (Fig. 3$)^{52)}$. These food ingredients contain isothiocyanates, polysulfides, and/or iodine in common; therefore, we hypothesized that these compounds were the causative agents. In fact, their standards enhanced the thermal $Z$ isomerization of lycopene (Fig. 3 ${ }^{52)}$. Although ample studies demonstrated that iodine promotes carotenoid $Z$ isomerization, to the best of our knowledge, this is the first report to demonstrate that isothiocyanates and polysulfides have a $Z$-isomerization-promoting effect. Carotenoid isomerization using food-derived organic molecule catalysts, such as isothiocyanates and polysulfides, is considered to be a safe and environmentally friendly technology. The hypothesized isomerization mechanism of carotenoids by isothiocyanates is described below ${ }^{42,65)}$ :

$$
\begin{aligned}
& (\text { Carotenoid })_{E}+(\text { Isothiocyanate }) \rightleftarrows\left(\text { Carotenoid } \bullet{ }^{+}\right)_{E}+ \\
& \left(\text { Isothiocyanate } \bullet^{-}\right) \\
& \left(\text {Carotenoid } \bullet^{+}\right)_{E} \rightleftarrows\left(\text { Carotenoid }^{+}{ }^{+}\right)_{Z} \\
& \left(\text { Carotenoid } \bullet^{+}\right)_{Z}+\left(\text { Isothiocyanate } \bullet^{-}\right) \rightleftarrows\left(\text { Carotenoid }_{Z}\right)^{+} \\
& (\text {Isothiocyanate })
\end{aligned}
$$

Isothiocyanates (isothiocyanate group) have powerful electrophilicity, and their properties accordingly enhance carotenoid $E / Z$-isomerization (1-3). The possible isomerization mechanism of carotenoids by polysulfides (RS-SR) is as follows ${ }^{42,65,66)}$ :

$$
\begin{aligned}
& (\mathrm{RS}-\mathrm{SR}) \rightleftarrows 2(\mathrm{RS} \bullet) \\
& (\text { Carotenoid })_{E}+(\mathrm{RS} \bullet) \rightleftarrows(\text { RS-Carotenoid } \bullet)_{E} \\
& (\text { RS-Carotenoid } \bullet)_{E} \rightleftarrows(\text { RS-Carotenoid } \bullet)_{Z} \\
& (\text { RS-Carotenoid } \bullet)_{Z} \rightleftarrows(\text { Carotenoid })_{Z}+(\mathrm{RS} \bullet)
\end{aligned}
$$

The sulfide bond (S-S) cleavage of polysulfides (4) is induced by heat treatment, and the resulting thiyl radicals $(\mathrm{RS} \bullet$ ) would enhance the carotenoid $E / Z$-isomerization (5-7).

As there are various molecular species present in isothiocyanates and polysulfides, we investigated the effect of these species on the $Z$-isomerization efficiency of carotenoids ${ }^{42)}$. Specifically, the effects of eight isothiocyanates [methyl isothiocyanate, ethyl isothiocyanate, isopropyl isothiocyanate, isobutyl isothiocyanate, hexyl isothiocyanate, allyl isothiocyanate, benzyl isothiocyanate, and 3-(methylthio) propyl isothiocyanate]as well as seven polysulfides (dimethyl disulfide, diethyl disulfide, diallyl disulfide, dimethyl trisulfide, dipropyl trisulfide, diisopropyl trisulfide, and diallyl trisulfide) on the thermal $Z$-isomerization of three commercially important carotenoids (lycopene, $\beta$-carotene, and astaxanthin)were investigated. Consequently, all isothiocyanates and polysulfides were observed

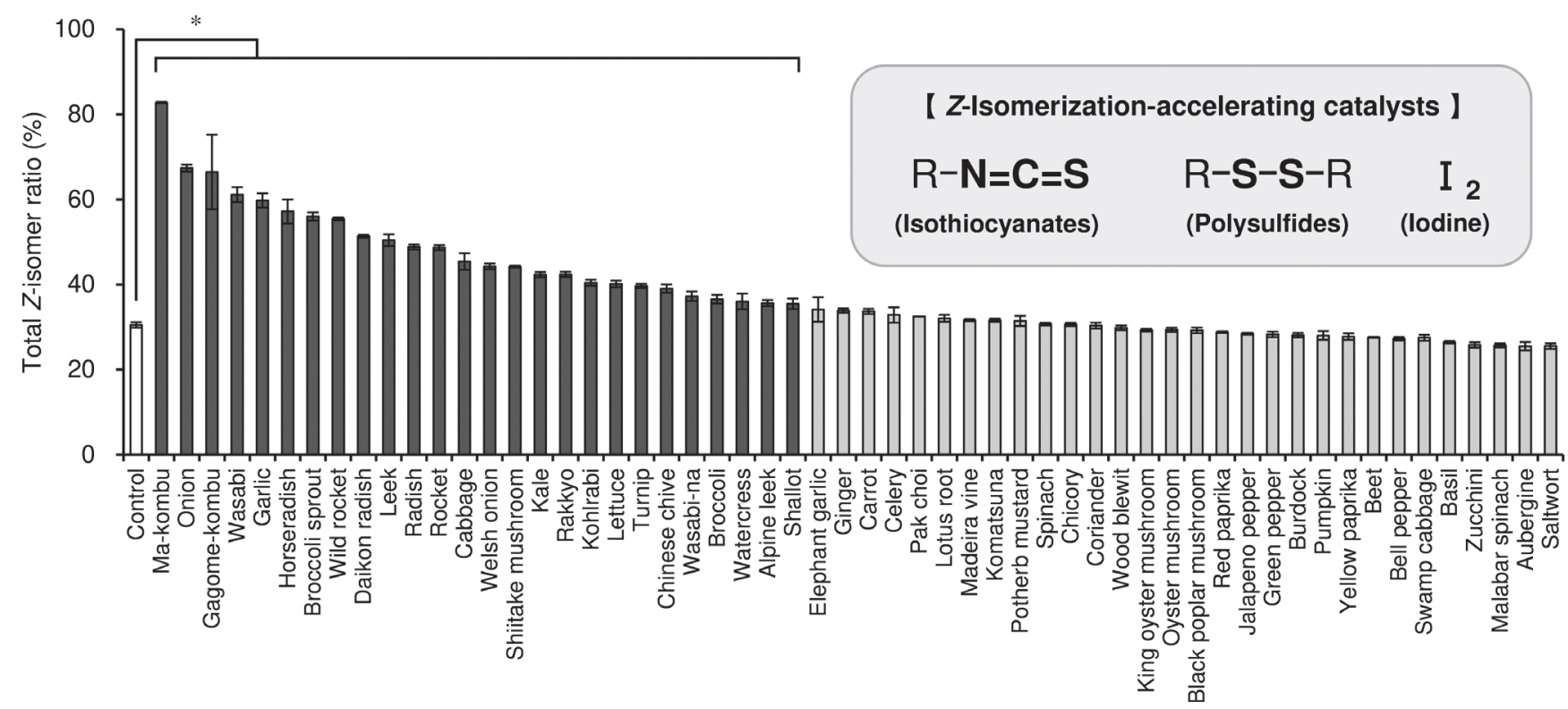

Fig. 3 Effect of food ingredients on the total $Z$-isomer ratio of lycopene in tomato puree containing $5 \%$ olive oil after heating at $80^{\circ} \mathrm{C}$ for $1 \mathrm{~h}$ and chemical structures of plant-derived $Z$-isomerization-accelerating catalysts (isothiocyanates, polysulfides, and iodine) for carotenoid isomerization ${ }^{42,52)}$. Asterisk $(*)$ indicates a statistically significant difference from the control group at $p<0.05$. 


\section{Honda}

to significantly enhance the thermal $Z$-isomerization of carotenoids-particularly hexyl and benzyl isothiocyanates and dimethyl and diallyl trisulfides-compared to the control(in the absence of the catalysts). In polysulfides, the $Z$-isomerization-promoting effect was directly proportional to the length of the sulfide bond. For example, when dimethyl disulfide and diallyl trisulfide were used, the total $Z$-isomer ratios of lycopene after the heating were 26.2 and $68.0 \%$, respectively. Moreover, we confirmed that an isothiocyanate, allyl isothiocyanate, which is inexpensive and relatively easily available in food grade and high purity, can effectively promote the carotenoid isomerization in vegetable oils and subcritical fluids ${ }^{27,44,47)}$. It is expected that these food-derived organic molecule catalysts will be effectively used to develop green and efficient isomerization technologies in the future.

\section{Application of Carotenoid Isomerization Technology}

Naturally predominant (all-E)-carotenoids have high crystallinity and low solubility in media, resulting in low carotenoid processing efficiency ${ }^{14,26,30,31)}$, and have low bioavailability, resulting in low pigmentation efficiency of flesh and egg yolk in seafood and laying hens, respectively ${ }^{7,34,35)}$; these are often major problems for the industrial use of carotenoids. Carotenoid isomerization induces significant changes in physicochemical properties, bioavailability, and biological activities ${ }^{14,26)}$. We recently found that these changes can utilize the improvements in carotenoid processing efficiency (e.g., extraction and micronization) $)^{32,33,41)}$ and hen's egg yolk pigmentation efficiency ${ }^{34,35)}$. In this section, changes in the basic characteristics of carotenoids (i.e., physicochemical properties, bioavailability, and bio- logical activities) with $E / Z$-isomerization have been outlined, along with the potential industrial applications of the isomerization technology.

\subsection{Improved efficiency of carotenoid processing}

(all-E)-Carotenoids have high crystallinity and low solubility in various media, including vegetable oils and supercritical $\mathrm{CO}_{2}{ }^{14,26,30-32)}$. These characteristics reduce the efficiency of various steps in carotenoid processing, such as extraction, water dispersion, and micronization ${ }^{32,33,41,67)}$. The $Z$-isomerization of carotenoids induced a reduction in their crystallinity, i.e., in X-ray diffraction(XRD) analysis, the peak intensity markedly decreased with increasing $Z$ isomer ratio of carotenoids (Fig. 4A). Moreover, in scanning electron microscopy (SEM) analysis, the transformation of crystals into amorphous was observed with increasing the $Z$-isomer ratio (Fig. 4B $)^{30,31)}$. Upon increasing the $Z$-isomer ratio of carotenoids, their solubilities in organic solvents and supercritical $\mathrm{CO}_{2}$ were drastically improved, e.g., the solubilities of (all- $E$ ) - $\beta$-carotene in ethanol, acetone, and hexane at $20^{\circ} \mathrm{C}$ were $20.0,137.5$, and $408.0 \mathrm{mg} / \mathrm{mL}$, respectively, whereas the solubilities of $Z$-isomer-rich $\beta$-carotene (total $Z$-isomer ratio $=89.8 \%)$ increased to $5493.2,6592.1$, and $6646.1 \mathrm{mg} / \mathrm{mL}$, respectively (Fig. 4C) ${ }^{29-31)}$. Utilizing these changes in the physicochemical properties of carotenoids with the $Z$-isomerization, we could successfully improve the processing efficiency of carotenoids ${ }^{14,26)}$. For example, thermal $Z$-isomerization pre-treatment of lycopene contained in dried tomato pulp markedly improved lycopene extraction efficiency using organic solvents and supercritical $\mathrm{CO}_{2}{ }^{32)}$. When the dried tomato pulp containing $1 \%$ olive oil was heated at $150^{\circ} \mathrm{C}$ for $1 \mathrm{~h}$, the total $Z$-isomer ratio increased from $8.8 \%$ to $75.7 \%$. Subsequently, lycopene was extracted from the dried tomato pulps with or
A

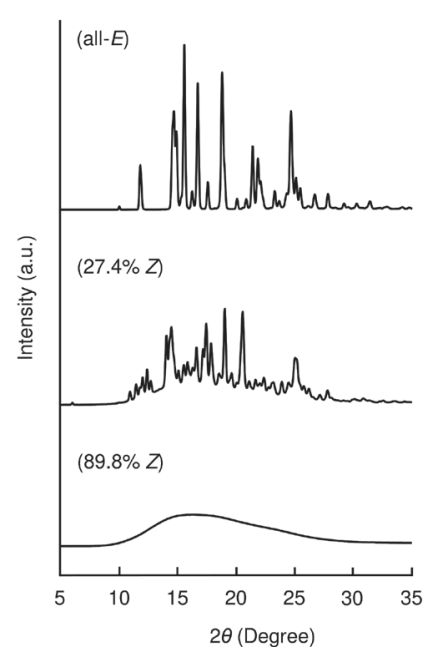

B

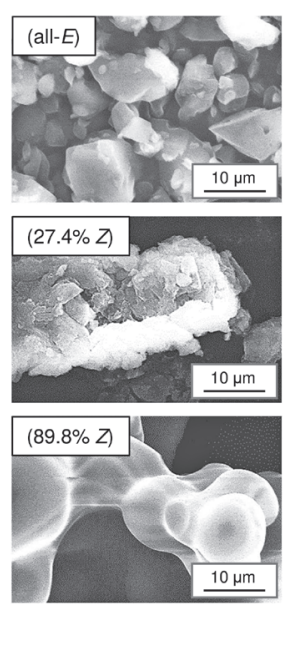

C

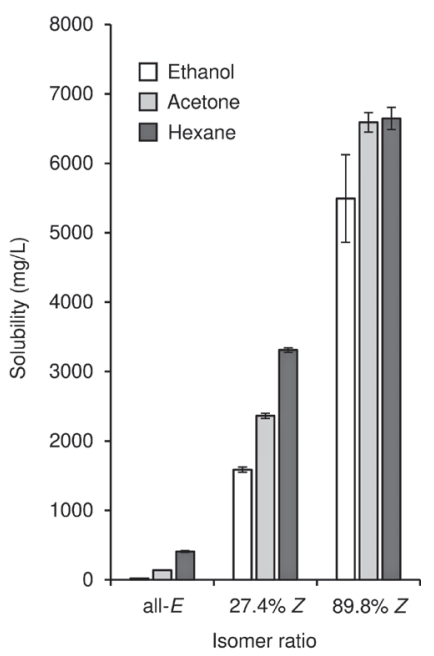

Fig. 4 Effect of the isomer ratio (all- $E$-isomer and total $Z$-isomer ratio of 27.4 and 89.8\%) of $\beta$-carotene on (A) XRD patterns, (B) SEM images, and (C) solubility in organic solvents (ethanol, acetone, and hexane) ${ }^{30)}$. 
without the $Z$-isomerization pre-treatment using ethanol, ethyl acetate, and supercritical $\mathrm{CO}_{2}$. When the extraction was conducted without the pre-treatment, the lycopene recovery rates were $6.3,48.5$, and $6.5 \%$, respectively, whereas with the pre-treatment, the lycopene recovery rates were observed to be $75.9,96.3$, and $27.6 \%$, respectively. This improvement could be attributed to an increase in the solubility of lycopene with the $Z$-isomerization. The fact that the total $Z$-isomer ratio of lycopene in the resulting extracts was higher than that in the extraction raw material (dried tomato pulp) supports this hypothesis. Furthermore, we compared the water distribution efficiency (encapsulation efficiency) of all- $E$-isomer-rich (total $Z$-isomer ratio $=1.9 \%$ ) and $Z$-isomer-rich (total $Z$-isomer ratio $=$ $79.1 \%$ ) $\beta$-carotene using Tween 20 as an emulsifier via the emulsification-evaporation technique ${ }^{67)}$. When $Z$-isomerrich $\beta$-carotene was used, the encapsulation efficiency was 21.2 times higher than that using the all- $E$-isomer rich $\beta$-carotene. This could be due to the fact that $\beta$-carotene $Z$-isomers have lower crystallinity and higher solubility in the medium (organic phase) than the all-E-isomer. Several studies have reported that the micronization efficiency of carotenoids is also enhanced by $Z$-isomerization pre-treatment ${ }^{33,48,67)}$. Kodama et $a l .{ }^{33)}$ reported that $Z$-isomerization pre-treatment of lycopene improved its micronization efficiency via a solution-enhanced dispersion by supercritical fluids (SEDS) approach (Fig. 5A). When (all-E)-lycopene was treated by the SEDS process at $40^{\circ} \mathrm{C}$ and $10 \mathrm{MPa}$, particles with an average size of $3.6 \mu \mathrm{m}$ were obtained(Fig. 5B), whereas when the SEDS treatment was conducted using $Z$-isomer-rich lycopene (total $Z$-isomer ratio $=97.8 \%$ ) prepared from the all- $E$-isomer via thermal treatment, particles with an average size of $75 \mathrm{~nm}$ were obtained(Fig. 5C). As mentioned above, $Z$-isomerization pre-treatment of carotenoids is an important technology for improving their processing efficiency. Moreover, the pre-treatment also enhances the $Z$-isomer ratio of the resulting products ${ }^{32,41,67)}$, which may lead to superior health-promoting effects.

\subsection{Enhanced health-promoting effects of carotenoids}

3.2.1 Enhanced bioavailability and bioaccumulation of carotenoids

The health benefits of carotenoids are considered to vary greatly between the all- $E$ and $Z$-isomers ${ }^{14,26)}$. Therefore, it is important to understand the differences properly and accordingly develop products that can exploit the characteristics of each isomer. Several studies have demonstrated that various carotenoid $Z$-isomers, such as lycopene, lutein, and astaxanthin, possess greater bioavailability than the all- $E$-isomers ${ }^{16,18,19,20)}$. Moreover, our group recently elucidated that $Z$-isomers of carotenoids (lycopene, $\beta$-carotene, lutein, and astaxanthin) exhibit excellent tissue accumulation efficiency (Table 1) ${ }^{19,20)}$. For example, an oral administration trial in rats fed with all- $E$-isomer-rich lycopene diet (total $Z$-isomer ratio $=0.5 \%$ ) or the $Z$-isomer-rich lycopene $\operatorname{diet}($ total $Z$-isomer ratio $=80.8 \%$ ) showed that the latter diet induced 11.6-, 4.6-, 5.8-, 14.0-, 3.0-, and 2.5-fold increases in lycopene concentrations in the liver, lung, kidney, adrenal, testis, and skin, respectively, compared to the former $\operatorname{diet}^{19)}$. It is considered that increasing carotenoid levels in the body may result in various health benefits $^{3,4,68)}$; thus, the intake of diets rich in carotenoid $Z$-isomers, rather than (all- $E$ )-carotenoids, is recommended in terms of bioavailability and bioaccumulation. In contrast, several studies have indicated that $\beta$-carotene $Z$-isomers derived from the alga Dunaliella are less bioavailable than the all- $E$-isomer ${ }^{25,69,70)}$. This outcome directly opposes the results of our study ${ }^{19)}$, and one of the possible reasons for this might be the difference in isomer species. The primary $\beta$-carotene $Z$-isomer of Dunaliella is the $9 Z$-isomer ${ }^{25,69,70)}$,
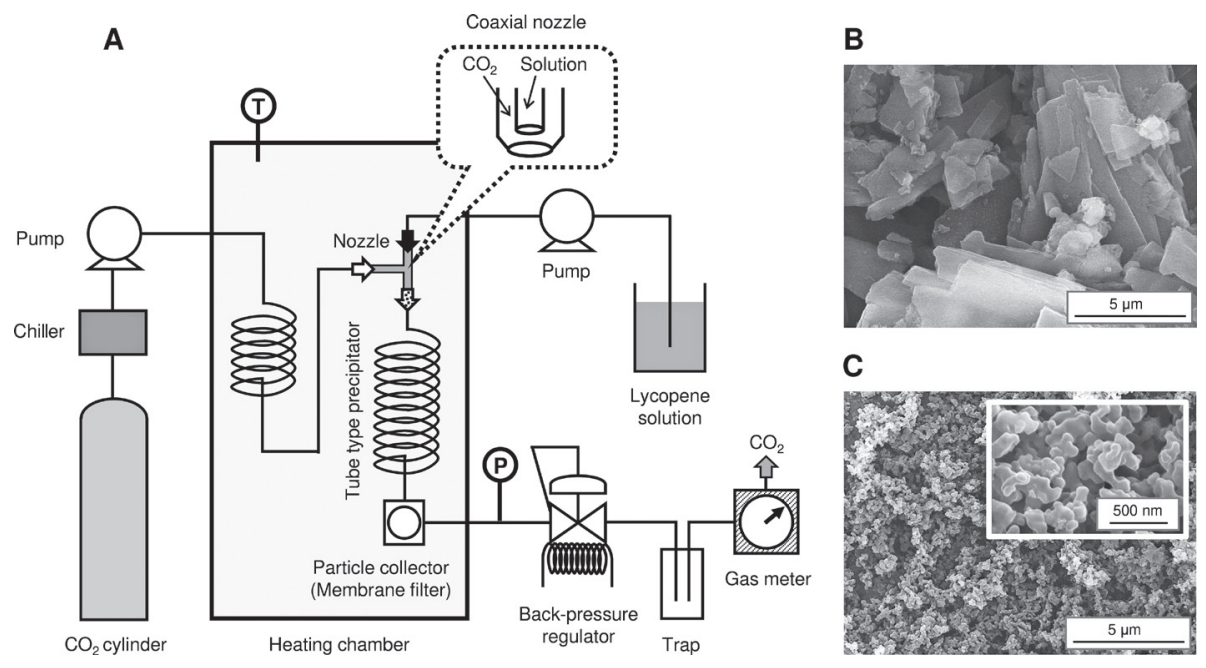

Fig. 5 (A) Schematic diagram of the SEDS process for lycopene micronization and SEM images of lycopene particles after processing at $40^{\circ} \mathrm{C}$ and $10 \mathrm{MPa}$ obtained from (B) (all-E) -lycopene and (C) $Z$-isomer-rich lycopene ${ }^{33)}$. 


\section{Honda}

Table 1 Effects of oral administration of all- $E$ - or $Z$-isomer-carotenoids (lycopene, $\beta$-carotene, lutein, and astaxanthin) on the plasma and tissue concentrations in rats after 2 -week feeding of the

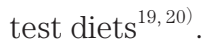

\begin{tabular}{|c|c|c|c|c|c|c|}
\hline \multirow[b]{3}{*}{ Carotenoid } & \multirow[b]{3}{*}{ Fraction } & \multicolumn{4}{|c|}{ Concentration $(\mathrm{pmol} / \mathrm{mL}$ or $\mathrm{pmol} / \mathrm{g})$} & \multirow[b]{3}{*}{ Significant } \\
\hline & & \multicolumn{2}{|c|}{ all- $E$-Isomer-rich diet } & \multicolumn{2}{|c|}{$Z$-Isomer-rich diet } & \\
\hline & & Mean & SEM & Mean & SEM & \\
\hline \multirow[t]{8}{*}{ Lycopene } & Plasma & 3.1 & 0.3 & 19.3 & 2.4 & * \\
\hline & Liver & 1573.7 & 327.2 & 18305.4 & 3277.9 & $* *$ \\
\hline & Lung & 13.5 & 2.7 & 62.6 & 8.1 & $* *$ \\
\hline & Kidney & 7.3 & 0.5 & 42.2 & 4.5 & $* *$ \\
\hline & Adrenal & 80.0 & 13.3 & 1120.4 & 135.3 & $* *$ \\
\hline & Prostate & ND & & 24.9 & 7.2 & $*$ \\
\hline & Testis & 12.8 & 2.3 & 38.5 & 6.1 & * \\
\hline & Skin & 3.8 & 0.7 & 9.6 & 1.4 & $*$ \\
\hline \multirow[t]{7}{*}{$\beta$-Carotene } & Plasma & 1.0 & 0.1 & 5.3 & 1.6 & \\
\hline & Liver & 419.5 & 127.5 & 3322.4 & 591.9 & $*$ \\
\hline & Lung & 16.9 & 5.3 & 37.7 & 5.1 & * \\
\hline & Kidney & 2.6 & 0.9 & 4.9 & 0.5 & $*$ \\
\hline & Adrenal & 67.9 & 19.2 & 838.0 & 147.0 & ** \\
\hline & Prostate & 5.4 & 1.2 & 17.0 & 3.5 & * \\
\hline & Testis & 1.6 & 0.5 & 10.2 & 1.7 & $* *$ \\
\hline \multirow[t]{7}{*}{ Lutein } & Plasma & 5.3 & 0.7 & 19.8 & 3.3 & * \\
\hline & Liver & 720.2 & 145.4 & 1414.2 & 160.7 & $*$ \\
\hline & Lung & 29.3 & 3.9 & 46.2 & 4.9 & * \\
\hline & Kidney & 7.3 & 0.7 & 15.6 & 1.4 & $* *$ \\
\hline & Prostate & 9.1 & 0.9 & 20.5 & 2.8 & * \\
\hline & Testis & 2.3 & 0.2 & 9.6 & 1.1 & $* *$ \\
\hline & Skin & 1.8 & 0.9 & 6.7 & 0.4 & $* *$ \\
\hline \multirow[t]{10}{*}{ Astaxanthin } & Plasma & 2.4 & 0.9 & 165.2 & 44.1 & $*$ \\
\hline & Liver & 145.9 & 35.3 & 355.3 & 13.9 & $* *$ \\
\hline & Lung & 12.8 & 3.5 & 468.6 & 45.7 & $* *$ \\
\hline & Kidney & 119.7 & 36.9 & 527.0 & 115.4 & $*$ \\
\hline & Adrenal & 35.6 & 25.9 & 384.6 & 36.5 & $* *$ \\
\hline & Prostate & 10.9 & 2.4 & 205.3 & 13.8 & $* *$ \\
\hline & Testis & 6.8 & 1.0 & 70.5 & 2.6 & $* *$ \\
\hline & Skin & 18.9 & 6.1 & 230.1 & 16.4 & $* *$ \\
\hline & Eye & ND & & 44.7 & 4.6 & $* *$ \\
\hline & Cerebral cortex & 74.0 & 16.6 & 80.2 & 11.2 & \\
\hline
\end{tabular}

Values represent the means and SEM $(n=5)$. Asterisks $(*)$ indicate a statistically significant difference in each row $\left({ }^{*} p<0.05,{ }^{*} p<0.01\right.$, Welch's $t$-test $)$. ND $=$ not detected substantially.

whereas the $13 Z$-isomer is the primary isomer in our study $^{19)}$. Evidently, the $(9 Z)-\beta$-carotene possesses less bioavailability than the all-E- and $13 Z$-isomers. As little research has been conducted on the differences in bioavail- ability among carotenoid $Z$-isomers, further investigation on this subject is necessitated in the future.

3.2.2 Enhanced biological activities of carotenoids

Numerous studies have demonstrated that several bio- 
Table 2 Summary of representative studies on differences in the bioavailability and biological activities among $E /$ $Z$-isomers of commercially important carotenoids (lycopene, $\beta$-carotene, lutein, and astaxanthin).

\begin{tabular}{|c|c|c|c|c|}
\hline Carotenoids & Evaluation & Evaluation method & Outline of result & References \\
\hline \multirow[t]{7}{*}{ Lycopene } & Bioavailability & Oral study in humans & $(Z)>($ all- $E)$ & $16-18$ \\
\hline & " & Oral study in rats & $(Z)>($ all- $E)$ & 19 \\
\hline & Antioxidant activity & $\begin{array}{l}\text { Singlet oxygen quenching } \\
\text { activity assay }\end{array}$ & $\begin{array}{l}(5 Z) \approx(\text { all- }-E) \geq(9 Z) \approx(13 Z) \approx \\
\left(7 Z, 9 Z, 7^{\prime} Z, 9^{\prime} Z\right)\end{array}$ & 76 \\
\hline & " & TEAC and LPSC assays & $(Z) \geq($ all- $E)$ & 71,77 \\
\hline & " & $\mathrm{MbFe}^{\mathrm{III}}$ lipid peroxidation assay & $\begin{array}{l}(5 Z)>(\text { all }-E) \approx(9 Z) \approx(13 Z) \approx \\
\left(7 Z, 9 Z, 7^{\prime} Z, 9^{\prime} Z\right)\end{array}$ & 77 \\
\hline & " & FRAP assay & $($ all-E) $\approx(Z)$ & 77 \\
\hline & Antiobesity activity & 3T3-L1 adipocyte cell model & $($ all- $E) \approx(5 Z)$ & 80 \\
\hline \multirow[t]{7}{*}{$\beta$-Carotene } & Bioavailability & Oral study in humans & $($ all- $E)>(9 Z)$ & 25,70 \\
\hline & " & Oral study in ferrets & $($ all- $E)>(9 Z)$ & 69 \\
\hline & " & Oral study in rats & $(Z)>($ all- $E)$ & 19 \\
\hline & Antioxidant activity & TEAC assay & $($ all-E) $\approx(Z)$ & 71 \\
\hline & " & FRAP assay & $($ all-E) $\approx(Z)$ & 81 \\
\hline & " & CL assay & $($ all-E) $\approx(9 Z) \approx(13 Z)>(15 Z)$ & 81 \\
\hline & Provitamin A activity & Enzymatic assay & $($ all-E) $>(Z)$ & 79 \\
\hline \multirow[t]{5}{*}{ Lutein } & Bioavailability & Oral study in rats & $(Z)>($ all- $E)$ & 19 \\
\hline & " & Caco-2 cell model & $($ all-E) $>(Z)$ & 72 \\
\hline & Antioxidant activity & CAA assay & $($ all-E) $\approx(Z)$ & 72 \\
\hline & " & FRAP assay & $\left(13^{\prime} Z\right)>(9 Z)>($ all- $E)$ & 72 \\
\hline & " & DPPH and ORAC assays & $\left(13^{\prime} Z\right)>($ all- $E) \approx(9 Z)$ & 72 \\
\hline \multirow[t]{8}{*}{ Astaxanthin } & Bioavailability & Oral study in humans & $(Z)>($ all- $E)$ & 82,83 \\
\hline & " & Oral study in rats & $(Z)>($ all- $E)$ & 20 \\
\hline & " & Oral study in hens & $(Z)>($ all- $E)$ & 35 \\
\hline & Antioxidant activity & ORAC and PCL assays & $(Z) \geq($ all- $E)$ & 22 \\
\hline & " & DPPH assay & $(9 Z)>($ all- $E) \approx(13 Z)$ & 22 \\
\hline & " & CAA assay & $(13 Z)>($ all-E $)>(9 Z)$ & 22 \\
\hline & Anti-inflammatory activity & Caco- 2 cell model & $(Z) \geq($ all- $E)$ & 23 \\
\hline & Antiaging activity & Caenorhabditis elegans model & $(9 Z)>($ all- $E)>(13 Z)$ & 75 \\
\hline
\end{tabular}

TEAC, Trolox equivalent antioxidant capacity; LPSC, luminol-chemiluminescence peroxyl radical scavenging capacity; FRAP, ferric reducing activity; CL, chemiluminescence; CAA, cellular antioxidant activity; DPPH,

2,2-diphenyl-1-picrylhydrazyl; ORAC, oxygen radical absorbing capacity; PCL, photochemiluminescence.

logical activities, such as antioxidant, anti-inflammatory, antiaging, and anticancer activities, vary significantly among carotenoid isomers ${ }^{14,22-24,26,71-75)}$. Yang et al. ${ }^{22)}$ evaluated the antioxidant activity of astaxanthin isomers using various assay methods and observed that the strength (order) of the activity of each isomer depends on the assay method: the $9 Z$ - and $13 Z$-isomers exhibited greater activity than the all- $E$-isomer in the oxygen radical absorbing capacity (ORAC) assay; the 13Z-isomer exhibited greater activity than the all- $E$ - and $9 Z$-isomers in the 2,2-diphenyl1-picrylhydrazyl (DPPH) assay; the antioxidant activity was reduced in the order of $13 Z$-, all- $E$-, and $9 Z$-isomers in the determination of cellular antioxidant activity (CAA) assay. In addition, it has been reported that the strength (order) of antioxidant activity among the isomers present in other carotenoids (e.g., lutein, canthaxanthin, and fucoxanthin) differs depending on the assay method, wherein $Z$-isomers have an activity equal to or greater than that of the all- $E$ isomers ${ }^{71-74)}$. Conversely, several studies indicated that (all-E)-carotenoids exhibit higher (or equal) antioxidant activity than the $Z$-isomers in certain assay methods, such as lycopene in singlet oxygen quenching activity assay and 


\section{Honda}
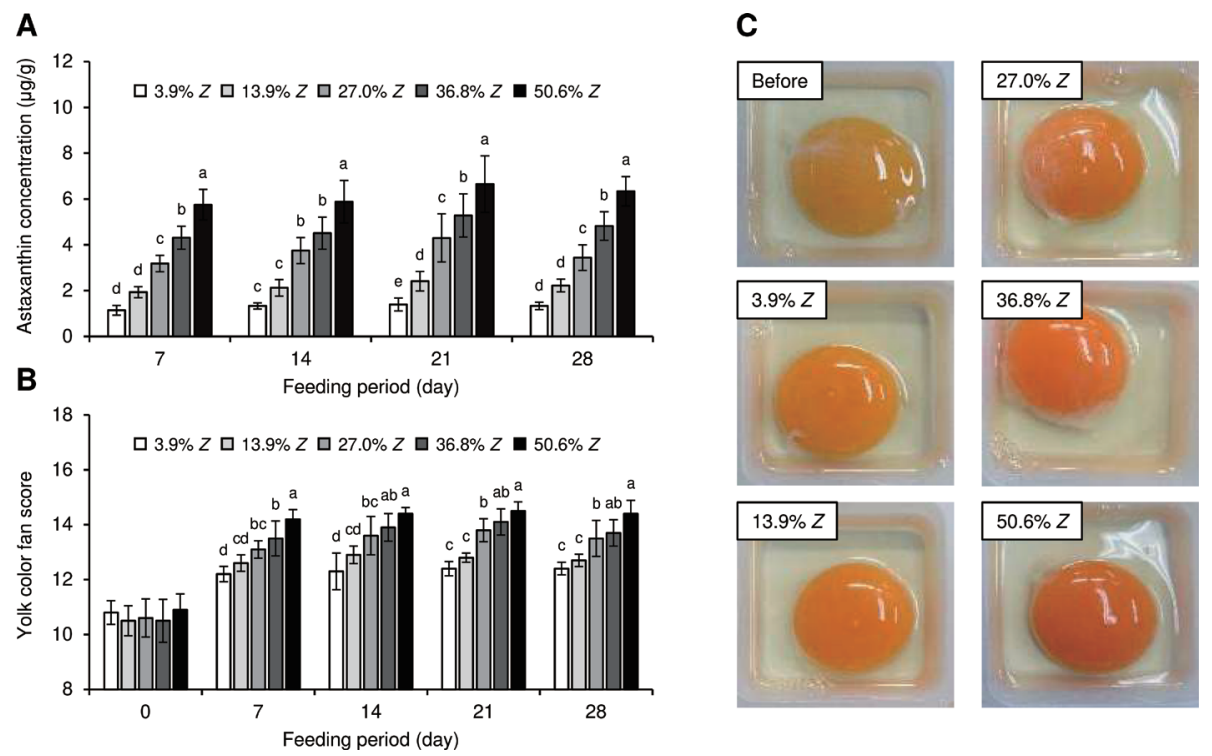

Fig. 6 Effects of feeding diets with different astaxanthin isomer ratios (total $Z$-isomer ratio of 3.9, 13.9, 27.0, 36.8, and $50.6 \%$ ) to laying hens for 28 days on (A) astaxanthin concentration, (B) yolk color fan score, and (C) appearance of egg yolk ${ }^{35)}$. Means with different letters for each day are significantly different $(p<0.05)$, whereas means with similar letters are not different from each other.

zeaxanthin in Trolox equivalent antioxidant capacity (TEAC) assay $^{71,76)}$ (note that lycopene $Z$-isomers possess higher antioxidant activity than the all- $E$-isomer in TEAC and $\mathrm{MbFe}^{\mathrm{III}}$ lipid peroxidation assays ${ }^{71,77)}$ ). Moreover, it has been observed that (9Z)-astaxanthin has higher anti-inflammatory and antiaging activities ${ }^{23,75)},(9 Z)$-canthaxanthin exhibits higher pro-apoptotic activity ${ }^{78)}$, and fucoxanthin $Z$-isomers have greater anticancer activity ${ }^{24)}$ than their all- $E$-isomers. Therefore, for several carotenoids, the intake of the $Z$-isomers would be preferable in terms of not only bioavailability but also biological activities. However, it has been reported that $Z$-isomerization of $\beta$-carotene might induce a reduction in provitamin $\mathrm{A}$ activity ${ }^{79)}$; thus, it is considered to be preferable to consume the all- $E$-isomer for this carotenoid with regard to its bioavailability and biological activity. As described above, as $Z$-isomerization of carotenoids would result in "positive" or "negative" effects on their health-promoting effects (Table 2) ${ }^{14,26,80-83)}$, it is important to select and use the appropriate isomer according to the situation. Moreover, among the approximately 850 kinds of carotenoids in nature, only less than 10 types of carotenoids have been investigated for the effects of their isomerization on bioavailability and biological activity. Further progress in this field is expected in the future.

\subsection{Enhanced egg yolk pigmentation of laying hens}

Carotenoids are extensively used in feed applications as coloring agents for egg yolks in hens, flesh and skin of fish, and the body and exoskeleton of crustaceans. In the carotenoid market, the feed segment was estimated to account for the largest market share in $2019^{10)}$. However, the low pigmentation efficiency of carotenoids in egg yolk, flesh, skin, etc., typically poses a serious hindrance to the feed industry, possibly due to the low bioavailability of carotenoids in living animals. Therefore, we investigated the possibility of improving the pigmentation efficiency of hen egg yolk by utilizing the high bioavailability of carotenoid $Z$-isomers. Specifically, the effects of the $Z$-isomer ratio of lycopene and astaxanthin on their concentration and color fan score in egg yolk were examined ${ }^{34,35)}$. In both carotenoids, as the $Z$-isomer ratios in the diet increased, their concentrations in egg yolk and yolk color fan score increased significantly. For example, feeding a $Z$-isomer-rich astaxanthin diet (total $Z$-isomer ratio $=50.6 \%$ ) increased astaxanthin concentration in egg yolk by approximately five-fold and improved the color fan score by approximately two folds compared to that in hens fed an all- $E$-isomerrich diet (total $Z$-isomer ratio $=3.9 \%)(\text { Fig. 6 })^{35)}$. In this study, we also confirmed that when $Z$-isomer-rich astaxanthin (total $Z$-isomer ratio $=82.4 \%$ ) was fed to the hens, plasma astaxanthin concentration increased by more than five times compared to that in hens fed an all- $E$-isomer-rich astaxanthin $(\text { total } Z \text {-isomer ratio }=1.2 \%)^{35)}$. These results strongly suggest that $Z$-isomers of lycopene and astaxanthin have higher bioavailability than the all- $E$-isomers, thus exhibiting excellent accumulation efficiency in egg yolk. In addition, as the feeding of $Z$-isomer-rich carotenoids resulted in a high $Z$-isomer ratio in egg yolk ${ }^{34,35)}$, the bioavailability and biological activities of egg yolk carotenoids might be enhanced ${ }^{14,26)}$. Hence, the feeding of $Z$-isomerrich carotenoid diets to laying hens would improve not only egg quality but also the beneficial health effects of the egg. 
To date, the high pigmentation efficiency of carotenoid $Z$ isomers has been confirmed only in hen egg yolk in feed applications, and it is expected that this research will be extended to the fields of fish and crustacean feeds as well.

\section{Conclusions and Future Perspectives}

It has recently become evident that the utilization of carotenoid isomerization technology can improve not only the health-promoting effects but also the processing efficiency and usability ${ }^{14,26)}$. For widespread practical application of carotenoid isomerization technology, it is necessary to develop efficient $Z$-isomerization methods. Our group has recently developed an efficient and continuous carotenoid isomerization method with subcritical fluids ${ }^{44,47,48)}$ and discovered naturally occurring $Z$-isomerization-accelerating catalysts (isothiocyanates and polysulfides) ${ }^{42,52)}$. These findings could be key to the implementation of isomerization technology. On the other hand, carotenoid Zisomers are less stable than the naturally predominant all$E$-isomers, that is, prolonged storage at room temperature or higher leads to all- $E$-isomerization of carotenoid $Z$-isomers $^{38,54)}$. Thus, the improvement of their stability is an important aspect that must be overcome for the practical use of carotenoid $Z$-isomers. We reported that specific vegetable oils (e.g., sesame and rice bran oils) and antioxidants (e.g., $\alpha$-tocopherol and butylated hydroxytoluene)improved the storage stability of $Z$-isomers of lycopene and $\operatorname{astaxanthin}^{84,85)}$. However, despite these efforts, the stability of carotenoid $Z$-isomers has not been sufficiently improved, and further technical development is required. The advantages of biological activity and applications of carotenoid $Z$-isomers have only been partially revealed. In the future, it is expected that a wide range of biological activity assessment tests and application developments of carotenoid $Z$-isomers will be conducted to further demonstrate their usefulness.

\section{Acknowledgement}

I am grateful to Prof. Dr. Motonobu Goto and Dr. Wahyudiono (Nagoya University); Prof. Dr. Yutaka Itabashi(Hokkaido University); Dr. Munenori Takehara, Dr. Yoshinori Inoue, Prof. Dr. Tsutomu Kumagai, and Prof. Dr. Chitoshi Kitamura (The University of Shiga Prefecture); Dr. Yoshiaki Hayashi, Prof. Dr. Hakuto Kageyama, and Prof. Dr. Takashi Hibino(Meijo University); Dr. Takashi Maoka(Research Institute for Production Development); Prof. Dr. Kiyotaka Nakagawa and Dr. Soo Takasu(Tohoku University); Prof. Dr. Takanori Tsuda (Chubu University); Dr. Kazuya Murakami (University of Shizuoka); Hiroyuki Ueda, Tetsuya Fukaya, Kohei Ichihashi, Wataru Takada, and Takuma Hi- gashiura (Kagome Co., Ltd.); as well as Yuki Kawashima, Yukiko Osawa, Ikuo Kuroda, and Kazuaki Hirasawa(Eneos Co., Ltd.) for their kind help and constructive suggestions. This work was partially supported by the Adaptable and Seamless Technology Transfer Program through Targetdriven R\&D (A-STEP) from the Japan Science and Technology Agency (JST) (grant number: JPMJTR20U7) and JSPS KAKENHI (grant number: 21K14823).

\section{Conflict of Interest}

The authors declare that there are no conflicts of interest.

\section{References}

1) Maoka, T. Carotenoids as natural functional pigments. J. Nat. Med. 74, 1-16(2020).

2) Yabuzaki, J. Carotenoids Database: structures, chemical fingerprints and distribution among organisms. Database 2017, 1-11 (2017).

3) Böhm, V.; Lietz, G.; Olmedilla-Alonso, B.; Phelan, D.; Reboul, E. et al. From carotenoid intake to carotenoid blood and tissue concentrations-implications for dietary intake recommendations. Nut. Rev. 79, 544-573 (2021).

4) Eggersdorfer, M.; Wyss, A. Carotenoids in human nutrition and health. Arch. Biochem. Biophys. 652, 18-26 (2018).

5) Fiedor, J.; Burda, K. Potential role of carotenoids as antioxidants in human health and disease. Nutrients 6, 466-488 (2014).

6) de Carvalho, C.C.C.R.; Caramujo, M.J. Carotenoids in aquatic ecosystems and aquaculture: a colorful business with implications for human health. Front. Mar. Sci. 4, 93 (2017).

7) Honda, M.; Kawashima, Y.; Hirasawa, K.; Uemura, T.; Jinkun, S.; Hayashi, Y. Possibility of using astaxanthinrich dried cell powder from Paracoccus carotinifaciens to improve egg yolk pigmentation of laying hens. Symmetry 12, 923(2020).

8) Baswan, S.M.; Marini, A.; Klosner, A.E.; Jaenicke, T.; Leverett, J. et al. Orally administered mixed carotenoids protect human skin against ultraviolet A-induced skin pigmentation: A double-blind, placebocontrolled, randomized clinical trial. Photodermatol. Photoimmunol. Photomed. 36, 219-225 (2020).

9) Davinelli, S.; Nielsen, M.E.; Scapagnini, G. Astaxanthin in skin health, repair, and disease: A comprehensive review. Nutrients 10, 522 (2018).

10) MarketsandMarkets Research Private Ltd. https:// www.marketsandmarkets.com/Market-Reports/carot- 


\section{Honda}

enoid-market-158421566.html (accessed October 9, 2021).

11) Yang, C.; Yan, H.; Jiang, X.; Xu, H.; Tsao, R.; Zhang, L. Preparation of $9 Z$ - $\beta$-carotene and $9 Z$ - $\beta$-carotene highloaded nanostructured lipid carriers: Characterization and storage stability. J. Agric. Food Chem. 68, 1384413853 (2020).

12) Rehman, A.; Tong, Q.; Jafari, S.M.; Assadpour, E.; Shehzad, Q. et al. Carotenoid-loaded nanocarriers: A comprehensive review. Adv. Colloid Interface Sci. 275, 102048 (2020).

13) de Freitas Santos, P.D.; Rubio, F.T.V.; da Silva, M.P.; Pinho, L.S.; Favaro-Trindade, C.S. Microencapsulation of carotenoid-rich materials: A Review. Food Res. Int. 147, 110571 (2021).

14) Honda, M. Carotenoid isomers: A systematic review of the analysis, biological activity, physicochemical property, and methods for isomerization. in Studies in Natural Products Chemistry, Volume 68 (Rahman, A. ed.) . Elsevier B.V., pp. 173-220 (2021).

15) Khoo, H.E.; Prasad, K.N.; Kong, K.W.; Jiang, Y.; Ismail, A. Carotenoids and their isomers: Color pigments in fruits and vegetables. Molecules 16, 1710-1738(2011).

16) Cooperstone, J.L.; Ralston, R.A.; Riedl, K.M.; Haufe, T.C.; Schweiggert, R.M. et al. Enhanced bioavailability of lycopene when consumed as cis-isomers from tangerine compared to red tomato juice, a randomized, cross-over clinical trial. Mol. Nutr. Food Res. 59, 658669 (2015).

17) Burri, B.J.; Burri, B.J.; Chapman, M.H.; Neidlinger, T.R.; Seo, J.S. et al. Tangerine tomatoes increase total and tetra-cis-lycopene isomer concentrations more than red tomatoes in healthy adult humans. Int. J. Food Sci. Nutr. 60, 1-16 (2009).

18) Unlu, N.Z.; Bohn, T.; Francis, D.M.; Nagaraja, H.N. Lycopene from heat-induced cis-isomer-rich tomato sauce is more bioavailable than from all-trans-rich tomato sauce in human subjects. Br. J. Nutr. 98, 140146 (2007).

19) Honda, M.; Takasu, S.; Nakagawa, K.; Tsuda, T. Differences in bioavailability and tissue accumulation efficiency of (all- $E$ )-and $(Z)$-carotenoids: A comparative study. Food Chem. 361, 130119(2021).

20) Honda, M.; Murakami, K.; Osawa, Y.; Kawashima, Y.; Hirasawa, K.; Kuroda, I. Z-Isomers of astaxanthin exhibit greater bioavailability and tissue accumulation efficiency than the all-E-isomer. J. Agric. Food Chem. 69, 3489-3495 (2021).

21） Yang, C.; Zhang, H.; Liu, R.; Zhu, H.; Zhang, L.; Tsao, R. Bioaccessibility, cellular uptake, and transport of astaxanthin isomers and their antioxidative effects in human intestinal epithelial Caco-2 cells. J. Agric. Food Chem. 65, 10223-10232 (2017).

22) Yang, C.; Zhang, L.; Zhang, H.; Sun, Q.; Liu, R. et al.
Rapid and efficient conversion of all- $E$-astaxanthin to $9 Z$ - and $13 Z$-isomers and assessment of their stability and antioxidant activities. J. Agric. Food Chem. 65, 818-826 (2017).

23) Yang, C.; Hassan, Y.I.; Liu, R.; Zhang, H.; Chen, Y. et al. Anti-inflammatory effects of different astaxanthin isomers and the roles of lipid transporters in the cellular transport of astaxanthin isomers in Caco-2 cell monolayers. J. Agric. Food Chem. 67, 6222-6231(2019).

24） Nakazawa, Y.; Sashima, T.; Hosokawa, M.; Miyashita, K. Comparative evaluation of growth inhibitory effect of stereoisomers of fucoxanthin in human cancer cell lines. J. Funct. Foods 1, 88-97(2009).

25) Stahl, W.; Schwarz, W.; von Laar, J.; Sies, H.; All-trans $\beta$-carotene preferentially accumulates in human chylomicrons and very low density lipoproteins compared with the 9-cis geometrical isomer. J. Nutr. 125, 21282133(1995).

26) Honda, M.; Kageyama, H.; Hibino, T.; Zhang, Y.; Wahyudiono et al. Improved carotenoid processing with sustainable solvents utilizing $Z$-isomerization-induced alteration in physicochemical properties: A review and future directions. Molecules 24, 2149 (2019).

27) Honda, M.; Ichihashi, K.; Takada, W.; Goto, M. Production of $(Z)$-lycopene-rich tomato concentrate: A natural catalyst-utilized and oil-based study for practical applications. J. Agric. Food Chem. 68, 11273-11281 (2020).

28) Honda, M.; Horiuchi, I.; Hiramatsu, H.; Inoue, Y.; Kitamura, C. et al. Vegetable oil-mediated thermal isomerization of (all- $E$ )-lycopene: Facile and efficient production of Z-isomers. Eur. J. Lipid Sci. Technol. 118, 1588-1592 (2016).

29) Watanabe, Y.; Honda, M.; Higashiura, T.; Fukaya, T.; Machmudah, S. et al. Rapid and selective concentration of lycopene $Z$-isomers from tomato pulp by supercritical $\mathrm{CO}_{2}$ with co-solvents. Solvent Extr. Res. Dev. Jpn. 25, 47-57 (2018)

30) Honda, M.; Kodama, T.; Kageyama, H.; Hibino, T.; Wahyudiono et al. Enhanced solubility and reduced crystallinity of carotenoids, $\beta$-carotene and astaxanthin, by $Z$-isomerization. Eur. J. Lipid Sci. Technol. 120, 1800191 (2018).

31) Murakami, K.; Honda, M.; Takemura, R.; Fukaya, T.; Kubota, M. et al. The thermal $Z$-isomerization-induced change in solubility and physical properties of (all-E)lycopene. Biochem. Biophys. Res. Commun. 491, 317-322 (2017).

32) Honda, M.; Watanabe, Y.; Murakami, K.; Takemura, R.; Fukaya, T. et al. Thermal isomerization pre-treatment to improve lycopene extraction from tomato pulp. $L W T$ 86, 69-75 (2017).

33) Kodama, T.; Honda, M.; Takemura, R.; Fukaya, T.; Uemori, C. et al. Effect of the $Z$-isomer content on 
nanoparticle production of lycopene using solutionenhanced dispersion by supercritical fluids (SEDS). $J$. Supercrit. Fluids 133, 291-296 (2018).

34) Honda, M.; Ishikawa, H.; Hayashi, Y. Alterations in lycopene concentration and $Z$-isomer content in egg yolk of hens fed all- $E$-isomer-rich and $Z$-isomer-rich lycopene. Anim. Sci. J. 90, 1261-1269 (2019).

35) Honda, M.; Kawashima, Y.; Hirasawa, K.; Uemura, T.; Sun, J.; Hayashi, Y. Astaxanthin $Z$-isomer-rich diets enhance egg yolk pigmentation in laying hens compared to that in all-E-isomer-rich diets. Anim. Sci. J. 92, e13512 (2021).

36) Honda, M.; Takahashi, N.; Kuwa, T.; Takehara, M.; Inoue, Y.; Kumagai, T. Spectral characterisation of $Z$-isomers of lycopene formed during heat treatment and solvent effects on the $E / Z$ isomerisation process. Food Chem. 171, 323-329 (2015).

37) Honda, M.; Kudo, T.; Kuwa, T.; Higashiura, T.; Fukaya, T. et al. Isolation and spectral characterization of thermally generated multi-Z-isomers of lycopene and the theoretically preferred pathway to di-Z-isomers. Biosci. Biotechnol. Biochem. 81, 365-371 (2017).

38) Murakami, K.; Honda, M.; Takemura, R.; Fukaya, T.; Kanda, H.; Goto, M. Effect of thermal treatment and light irradiation on the stability of lycopene with high $Z$-isomers content. Food Chem. 250, 253-258 (2018).

39) Honda, M.; Igami, H.; Kawana, T.; Hayashi, K.; Takehara, M. et al. Photosensitized E/Z isomerization of (all$E)$-lycopene aiming at practical applications. J. Agric. Food Chem. 62, 11353-11356 (2014).

40) Honda, M.; Sato, H.; Takehara, M.; Inoue, Y.; Kitamura, C. et al. Microwave-accelerated $Z$-isomerization of (all$E)$-lycopene in tomato oleoresin and enhancement of the conversion by vegetable oils containing disulfide compounds. Eur. J. Lipid Sci. Technol. 120, 1800060 (2018).

41) Honda, M.; Watanabe, Y.; Murakami, K.; Hoang, N.N.; Wahyudiono et al. Enhanced lycopene extraction from gac (Momordica cochinchinensis Spreng.) by the $Z$ isomerization induced with microwave irradiation pretreatment. Eur. J. Lipid Sci. Technol. 120, 1700293 (2018).

42) Honda, M.; Kageyama, H.; Hibino, T.; Ichihashi, K.; Takada, W.; Goto, M. Isomerization of commercially important carotenoids (lycopene, $\beta$-carotene, and astaxanthin) by natural catalysts: Isothiocyanates and polysulfides. J. Agric. Food Chem. 68, 3228-3237 (2020).

43) Honda, M.; Kawana, T.; Takehara, M.; Inoue, Y. Enhanced $E / Z$ isomerization of (all- $E$ )-lycopene by employing iron (III) chloride as a catalyst. J. Food Sci. 80, C1453-C1459 (2015).

44) Honda, M.; Murakami, K.; Zhang, Y.; Goto, M. High-efficiency lycopene isomerization with subcritical ethyl acetate in a continuous-flow reactor. J. Supercrit. Fluids 178, 105383(2021).

45) Honda, M.; Kageyama, H.; Hibino, T.; Waditee-Sirisattha, R.; Fukaya, T. et al. Chemical-free approach for Zisomerization of lycopene in tomato powder: Hot air and superheated steam heating above the melting point of lycopene. Eur. J. Lipid Sci. Technol. 122, 1900327 (2020)

46) Yuan, J.P.; Chen, F. Isomerization of trans-astaxanthin to cis-isomers in organic solvents. J. Agric. Food Chem. 47, 3656-3660 (1999).

47) Honda, M.; Murakami, K.; Zhang, Y.; Goto, M. Rapid and continuous astaxanthin isomerization in subcritical ethanol. Ind. Eng. Chem. Res. 60, 14060-14068 (2021).

48) Zhang, Y.; Murakami, K.; Goto, M.; Honda, M. Continuous production of $Z$-isomer-rich $\beta$-carotene nanosuspensions utilizing subcritical fluid and a swirl-type mixer. ACS Food Sci. Technol. 1, 1652-1660 (2021).

49) Rathore, A.S.; Agarwal, H.; Sharma, A.K.; Pathak, M.; Muthukumar, S. Continuous processing for production of biopharmaceuticals. Prep. Biochem. Biotechnol. 45, 836-849 (2015).

50) Honda, M.; Murakami, K.; Watanabe, Y.; Higashiura, T.; Fukaya, T. et al. The $E / Z$ isomer ratio of lycopene in foods and effect of heating with edible oils and fats on isomerization of (all-E)-lycopene. Eur. J. Lipid Sci. Technol. 119, 1600389 (2017).

51) Honda, M.; Kageyama, H.; Murakami, K.; Hibino, T.; Osawa, Y. et al. Isomerization of Paracoccus carotinifaciens-derived carotenoids (astaxanthin, adonirubin, and adonixanthin) under subcritical water conditions. ACS Food Sci. Technol. 1, 1861-1868(2021).

52) Honda, M.; Kageyama, H.; Hibino, T.; Takemura, R.; Goto, M.; Fukaya, T. Enhanced Z-isomerization of tomato lycopene through the optimal combination of food ingredients. Sci. Rep. 9, 7979 (2019).

53) Saini, R.K.; Keum, Y.S. Carotenoid extraction methods: A review of recent developments. Food Chem. 240, 90-103 (2018).

54) Honda, M.; Sowa, T.; Kawashima, Y. Thermal- and photo-induced isomerization of all- $E$ - and $Z$-isomer-rich xanthophylls: Astaxanthin and its structurally-related xanthophylls, adonirubin, and adonixanthin. Eur. J. Lipid Sci. Technol. 122, 1900462 (2020).

55) Kuki, M.; Koyama, Y.; Nagae, H. Triplet-sensitized and thermal isomerization of all-trans, 7-cis, 9-cis, 13-cis, and 15-cis isomers of $\beta$-carotene: Configurational dependence of the quantum yield of isomerization via the $\mathrm{T}_{1}$ state. J. Phys. Chem. 95, 7171-7180 (1991).

56) Jensen, N.H.; Nielsen, A.B.; Wilbrandt, R. Chlorophyll $a$ sensitized trans-cis photoisomerization of alltrans- $\beta$-carotene. J. Am. Chem. Soc. 104, 6117-6119 (1982). 


\section{Honda}

57) Chen, B.H.; Chen, T.M.; Chien, J.T. Kinetic model for studying the isomerization of $\alpha$ - and $\beta$-carotene during heating and illumination. J. Agric. Food Chem. 42, 2391-2397 (1994).

58) Ideses, R.; Shani, A. Study of the radical mechanism of iodine-catalyzed isomerization of conjugated diene systems. J. Am. Oil Chem. Soc. 66, 948-952(1989).

59) Kessy, H.N.; Zhang, L.; Zhang, H. Lycopene $(Z)$-isomers enrichment and separation. Int. J. Food Sci. Technol. 48, 2050-2056(2013).

60) Honda, M.; Kageyama, H.; Hibino, T.; Sowa, T.; Kawashima, Y. Efficient and environmentally friendly method for carotenoid extraction from Paracoccus carotinifaciens utilizing naturally occurring $Z$-isomerization-accelerating catalysts. Process Biochem. 89, 146-154(2020).

61) Zhao, L.; Chen, F.; Zhao, G.; Wang, Z.; Liao, X.; Hu, X. Isomerization of trans-astaxanthin induced by copper (II) ion in ethanol. J Agric. Food Chem. 53, 96209623 (2005).

62) Rajendran, V.; Chen, B.H. Isomerization of $\beta$-carotene by titanium tetrachloride catalyst. J. Chem. Sci. 119, 253-258 (2007).

63) Honda, M.; Kageyama, H.; Hibino, T.; Ichihashi, K.; Takada, W.; Goto, M. Synergistic effects of food ingredients and vegetable oils on thermal isomerization of lycopene. J. Oleo Sci. 69, 1529-1540 (2020).

64) Honda, M.; Kageyama, H.; Hibino, T.; Zhang, Y.; Ichihashi, K. et al. Impact of global traditional seasonings on thermal $Z$-isomerization of (all- $E$ )-lycopene in tomato puree. LWT 116, 108565 (2019).

65) Honda, M.; Murakami, K.; Ichihashi, K.; Takada, W.; Goto, M. Enriched $(Z)$-lycopene in tomato extract via co-extraction of tomatoes and foodstuffs containing $Z$ isomerization-accelerating compounds. Catalysts 11, 462 (2021).

66) Ferreri, C.; Samadi, A.; Sassatelli, F.; Landi, L.; Chatgilialoglu, C. Regioselective cis-trans isomerization of arachidonic double bonds by thiyl radicals: the influence of phospholipid supramolecular organization. $J$. Am. Chem. Soc. 126, 1063-1072(2004).

67) Ono, M.; Honda, M.; Wahyudiono; Yasuda, K.; Kanda, H.; Goto, M. Production of $\beta$-carotene nanosuspensions using supercritical $\mathrm{CO}_{2}$ and improvement of its efficiency by $Z$-isomerization pre-treatment. J. Supercrit. Fluids 138, 124-131 (2018).

68) Woodside, J.V.; McGrath, A.J.; Lyner, N.; McKinley, M.C. Carotenoids and health in older people. Maturitas 80, 63-68(2015).

69) Erdman Jr, J.W.; Thatcher, A.J.; Hofmann, N.E.; Lederman, J.D.; Block, S.S. et al. All-trans $\beta$-carotene is absorbed preferentially to 9 -cis $\beta$-carotene, but the latter accumulates in the tissues of domestic ferrets (Mustela putorius puro). J. Nutr. 128, 2009-2013
(1998).

70) Morinobu, M.; Tamai, H.; Murata, T.; Manago, M.; Takenaka, H. et $a l$. Changes in $\beta$-carotene levels by longterm administration of natural $\beta$-carotene derived from Dunaliella bardawil in humans. J. Nutr. Sci. Vitaminol. 40, 421-430(1994).

71) Böhm, V.; Puspitasari-Nienaber, N.L.; Ferruzzi, M.G.; Schwartz, S.J. Trolox equivalent antioxidant capacity of different geometrical isomers of $\alpha$-carotene, $\beta$-carotene, lycopene, and zeaxanthin. J. Agric. Food Chem. 50, 221-226 (2002).

72) Yang, C.; Fischer, M.; Kirby, C.; Liu, R.; Zhu, H. et al. Bioaccessibility, cellular uptake and transport of luteins and assessment of their antioxidant activities. Food Chem. 249, 66-76 (2018).

73) Venugopalan, V.; Tripathi, S.K.; Nahar, P.; Saradhi, P.P.; Das, R.H.; Gautam, H.K. Characterization of canthaxanthin isomers isolated from a new soil Dietzia sp. and their antioxidant activities. J. Microbiol. Biotechnol. 23, 237-245 (2013).

74) Zhang, Y.; Fang, H.; Xie, Q.; Sun, J.; Liu, R. et al. Comparative evaluation of the radical-scavenging activities of fucoxanthin and its stereoisomers. Molecules 19, 2100-2113(2014).

75) Liu, X.; Chen, X.; Liu, H.; Cao, Y. Antioxidation and anti-aging activities of astaxanthin geometrical isomers and molecular mechanism involved in Caenorhabditis elegans. J. Funct. Foods 44, 127-136(2018).

76) Sakemi, Y.; Sato, K.; Hara, K.; Honda, M.; Shindo, K. Biological activities of $Z$-lycopenes contained in food. J. Oleo Sci. 69, 1509-1516(2020).

77) Müller, L.; Goupy, P.; Fröhlich, K.; Dangles, O.; CarisVeyrat, C.; Böhm, V. Comparative study on antioxidant activity of lycopene $(Z)$-isomers in different assays. $J$. Agric. Food Chem. 59, 4504-4511 (2011).

78) Venugopalan, V.; Verma, N.; Gautam, H.K.; Saradhi, P.P.; Das, R.H. 9-cis-Canthaxanthin exhibits higher pro-apoptotic activity than all-trans-canthaxanthin isomer in THP-1 macrophage cells. Free Radic. Res. 43, 100-105 (2009).

79) Nagao, A.; Olson, J.A. Enzymatic formation of 9-cis, 13-cis, and all-trans retinals from isomers of $\beta$-carotene. FASEB J. 8, 968-973(1994).

80) Fenni, S.; Astier, J.; Bonnet, L.; Karkeni, E.; Gouranton, E. et al. (all-E)-and (5Z)-Lycopene display similar biological effects on adipocytes. Mol. Nutr. Food Res. 63, 1800788(2019).

81) Mueller, L.; Boehm, V. Antioxidant activity of $\beta$-carotene compounds in different in vitro assays. Molecules 16, 1055-1069 (2011).

82) Coral-Hinostroza, G.N.; Ytrestøyl, T.; Ruyter, B.; Bjerkeng, B. Plasma appearance of unesterified astaxanthin geometrical $E / Z$ and optical $R / S$ isomers in men given single doses of a mixture of optical 3 and $3^{\prime} R / S$ iso- 
mers of astaxanthin fatty acyl diesters. Comp. Biochem. Physiol. C Toxicol. Pharmacol. 139, 99-110 (2004).

83) Østerlie, M.; Bjerkeng, B.; Liaaen-Jensen, S. Plasma appearance and distribution of astaxanthin $E / Z$ and $R /$ $S$ isomers in plasma lipoproteins of men after single dose administration of astaxanthin. J. Nutr. Biochem. 11, 482-490 (2000)

84) Murakami, K.; Honda, M.; Wahyudiono; Kanda, H.; Goto, M. Improved storage stability of lycopene $Z$-isomers utilizing edible media and antioxidants to promote practical applications. ACS Food Sci. Technol. 1,
1677-1686 (2021).

85) Honda, M.; Kageyama, H.; Hibino, T.; Osawa, Y.; Kawashima, Y. et al. Evaluation and improvement of storage stability of astaxanthin isomers in oils and fats. Food Chem. 352, 129371 (2021).

CC BY 4.0 (Attribution 4.0 International). This license allows users to share and adapt an article, even commercially, as long as appropriate credit is given. That is, this license lets others copy, distribute, remix, and build upon the Article, even commercially, provided the original source and Authors are credited. 